\title{
A Game Theoretic Analysis of Cryptocurrency Market for Sustainable Development of Smart Cities
}

\section{Rajani Singh}

CBS: Copenhagen Business School

Ashutosh Dhar Dwivedi ( $\nabla$ adhdw@dtu.dk)

DTU: Danmarks Tekniske Universitet https://orcid.org/0000-0001-8010-6275

\section{Agnieszka Wiszniewska-Matyszkiel}

University of Warsaw: Uniwersytet Warszawski

\section{Research Article}

Keywords: Differential Game, Dynamic Advertising, Stackelberg Competition, Market Share, Dynamic advertising, Cryptocurrency Market, Contest Theory, Smart Cities, Blockchain

Posted Date: June 25th, 2021

DOI: https://doi.org/10.21203/rs.3.rs-645368/v1

License: (c) (i) This work is licensed under a Creative Commons Attribution 4.0 International License. Read Full License 


\section{Abstract}

Cryptocurrency was first began to use in 2009 and features technology such as blockchain that is used in the development of smart cities. Game theory play an important role when designing secure economic system such as Bitcoin. In this paper, we study a dynamic game model of brand advertising in continuous time with the finite time horizon. The total payoff or profit of players or firms is discounted over time and the rate at which the firms attract the customers from its rival, called attraction rate, is taken from the economic theory of contest. As a novelty of our game model, the attraction rate of a firm depends on both: player's or firm's advertising effort and the advertising effort of players or firm's rivalry. We solve the game for Stackelberg equilibrium (with the leader and follower differing by information and/or the sequence of choosing strategies) as well as for Nash equilibrium. Further, we graphically compare the results obtained for the Stackelberg and the Nash equilibrium. Surprisingly, we have obtained that if the revenue per unit of market share is equal for Nash and Stackelberg equilibrium then the results for Nash player 1 overlaps with the leader and the results for Nash player 2 overlaps with follower. Finally, we present the application of our dynamic game model in the cryptocurrency market where two firms compete with each other for the cryptocurrency market share.

\section{Full Text}

This preprint is available for download as a PDF. 